the essential message is that the benefits of POEC far outweigh the risks, which remain very small indeed.

\section{Acknowledgements}

The authors would like to thank the doctors and pharmacists, both in the UK and NZ, who sent in the spontaneous reports that have been discussed in this article. They would also like to acknowledge Dr Ruth Savage of the Centre for Adverse Reactions Monitoring for her help in identifying and assessing the New Zealand spontaneous reports.

Statements on funding and competing interests

Funding. None identified.

Competing interests. None identified.

\author{
Mira Harrison-Woolrych, DM, MRCOG \\ Senior Research Fellow, Centre for Adverse Reactions \\ Monitoring, University of Otago Medical School, PO Box
}

913, Dunedin, New Zealand. E-mail: mira.harrisonwoolrych@stonebow.otago.ac.nz

Jane Woolley, BSc, PhD

Scientific Assessor, Post-licensing Division, Medicines Control Agency, Market Towers, 1 Nine Elms Lane, London SW8 $5 N Q, U K$

References

1 McCann M, Potter L. Progestin-only oral contraception: a comprehensive review. Contraception 1994; 50(6): S44-S49.

2 Fabunmi L, Perks N. Caesarean section scar ectopic pregnancy following postcoital contraception. J Fam Plann Reprod Health Care 2002: 28: 155-156.

3 WHO Task Force on Postovulatory Methods of Fertility Regulation. Randomised controlled trial of levonorgestrel versus the Yuzpe regimen of combined oral contraceptives for emergency contraception. Lancet 1998; 352: 428-433.

4 Inman WHW, Weber JCP. The United Kingdom. In: Inman WHW (ed.), Monitoring for drug safety. Lancaster: MTP Press, 1986; 13-47.

5 Harrison-Woolrych ML, Duncan A, Howe J, et al. Improving access to emergency contraception. BMJ 2001; 322: 186-187.

\title{
Homeopathy: a potent alternative
}

Have you ever wished you could offer your patients an additional form of treatment? Acquiring the skills of complementary medicine gives a practitioner another string to their bow. Homeopathy is one such string. When used by a doctor it can be fully integrated with conventional medicine and can be useful when conventional treatment fails. In this issue Dr Angela Jones discusses the use of homeopathy for premenstrual symptoms, including premenstrual syndrome (PMS) (pages 25-28). The value of conventional medicine is debatable for such conditions. She describes how homeopathy has many medicines to offer, including medicines to treat some of the unusual symptoms women describe such as specific food cravings or emotional symptoms.

Homeopathy was first described 200 years ago by a German physician, Dr Samuel Hahnemann (1755-1843). Hahnemann sought a system of medicine that was gentle, reliable and free of harmful effects. ${ }^{1}$ The principles of homeopathy and the concept of illness differ from those of conventional medicine. The cardinal principle of 'treating like with like' was first mentioned by Hippocrates. However, modern homeopathic doctors work in the same way as conventional colleagues. History, examination, investigation and diagnosis form part of the patient management. Prescribing is based on all aspects of the patient's condition including lifestyle and personality. Hahnemann developed homeopathy using detailed observations and early forms of clinical trials. Present day opponents of homeopathy argue that any beneficial effects (and they have to agree that these exist) must be due to placebo effect. There are difficulties conducting research in homeopathy. Randomised controlled trials (RCTs) present a particular difficulty as homeopathic treatment is individualised. Two patients with the same diagnosis may require entirely different medicines. In RCTs, patient groups are usually assigned to a standardised treatment while the control group receives placebo. However, some researchers have tested the effects of a single remedy on a particular condition, even though in practice practitioners would use a variety of different medicines. One example is Reilly's trial of homeopathy for hayfever, where subjects were randomised to receive either a single homeopathic medicine or placebo. ${ }^{2}$ Another is a double-blind RCT to evaluate the efficacy of a homeopathic medicine for influenza where nearly 500 patients received either Oscillococcinum ${ }^{\circledR}$ or placebo. ${ }^{3}$ Three meta-analyses ${ }^{4-6}$ have shown a positive response for homeopathy.

Funding is always a problem in research, and particularly so for complementary medicine. Despite the difficulties current research continues.

Having started in Germany, homeopathy continues to be popular there today. It is popular in other European countries including The Netherlands, Belgium, Austria, Greece, France and the UK. European royalty have supported homeopathy since it began. It is even more popular in India where it is often used as the primary method of treatment. There are many thousands of homeopathic doctors in India and over 100 homeopathic colleges. Mother Teresa embraced homeopathic medicine and set up her first homeopathic dispensary in Calcutta in 1950.

Homeopathy is becoming increasingly popular with patients and over-the-counter sales are increasing by 15-20\% each year. People are more concerned about drug toxicity, side effects and antibiotic resistance. They recognise the benefits of a holistic approach to care, time to tell their story, and an individual prescription.

Within the field of gynaecology and reproductive health care, homeopathy has many applications both in primary and secondary care. Treatment of PMS is just one of many conditions where homeopathy can be beneficial. Homeopathy can be used in addition to conventional medicine and may reduce the use of conventional drugs. Homeopathic medicines also have the advantage of being inexpensive. For example, the use of homeopathy to treat dysmenorrhoea may lead to a reduction in the use of analgesia or non-steroidal anti-inflammatory drugs (NSAIDs). Appropriate homeopathic medicines for dysmenorrhoea include Sepia (ink of the cuttle fish), Cuprum metallicum (copper) and Nux vomica (poison nut). Homeopathy can be used as an alternative treatment in nonserious conditions when a diagnosis has been established. Ipecacuanha (Ipecac-root), Belladonna and Sepia are three 
medicines useful for menorrhagia. ${ }^{8}$ Endometriosis, ${ }^{9}$ ovarian cysts, ${ }^{10}$ mastalgia ${ }^{8}$ and vaginal discharge $\mathrm{e}^{7}$ can all be treated with homeopathy. Homeopathy may help a patient while they wait for surgery or may alleviate symptoms while they take time to consider conventional treatment or their choices. Patients may find they develop side effects on conventional treatment or it is contraindicated, e.g. hormone replacement therapy. Homeopathic medicines that are useful for menopausal symptoms include Lachesis (snake venom), Sulphur and Pulsatilla (pasque flower). ${ }^{7}$ Patients undergoing treatment for gynaecological cancer or breast cancer may suffer distressing side effects. Homeopathy can assist with hot flushes from ovarian function suppression, ${ }^{11-13}$ mouth ulceration, nausea and vomiting with chemotherapy and the side-effects of radiotherapy. ${ }^{14} \mathrm{It}$ can help specific symptoms such as bone pain from secondary deposits, cough, loss of appetite and ulceration. It can offer help in terminal care to ease restlessness, mood lability and pruritus. ${ }^{12,15,16}$

Homeopathy can be used in the treatment of adult survivors of sexual abuse. Katz ${ }^{17}$ has found it helpful in her work in the Women's Clinic at the Royal London Homeopathic Hospital. She found that $60-70 \%$ of her patients had some experience of sexual abuse in their past history. Homeopathic medicines helped these patients reduce their physical suffering and some of the emotional consequences of the abuse. Another application is the treatment of sexual complaints. ${ }^{18}$ There are many medicines that can be used in a psychosexual medicine clinic, e.g. Lycopodium (club moss) for premature ejaculation and impotence ${ }^{18}$ or Ignatia (St Ignatius' bean) for loss of libido. ${ }^{18}$ Emotional factors are most important when choosing the indicated homeopathic medicine, making its use in a psychosexual medicine clinic well placed.

Other health care professionals such as nurses, pharmacists, midwives, podiatrists and dentists undertake training in homeopathy and use it in their field of practice. As homeopathy is safe in pregnancy midwives can find it useful in the treatment of nausea, vomiting, heartburn, backache and urinary frequency in pregnancy.,8 After delivery it can help bruising, pain, healing of surgical incisions and problems with breastfeeding. ${ }^{7,8}$

Finally, how can homeopathy help the doctor? I believe my training in homeopathy has improved my consultation skills, especially observation, listening and understanding. It has enhanced the range of options I can offer my patients and has increased my job satisfaction. I am part of the homeopathic community, which is full of enthusiastic, vibrant and optimistic people. And, if that is not enough, when work is getting the better of me, I know some medicines that help.
Statements on funding and competing interests Funding. None identified.

Competing interests. None identified.

Beccy Hobbs, DFFP, MFHom

Lead Clinician, Contraceptive and Sexual Health Service, Taunton Deane NHS Primary Care Trust, Somerset House, Lower Middle Street, Taunton TA1 1SF, UK and Associate Editor, Journal of Family Planning and Reproductive Health Care

References

1 Hahnemann S. Organon of medicine (6th edn). New Delhi: B Jain, 1993.

2 Reilly D, Taylor M, McSharry C, et al. Is homeopathy a placebo response? Lancet 1986; 2(8520): 881-886.

3 Ferley JP, Zmirou D, D'Adhemar D, et al. A controlled evaluation of a homeopathic preparation in the treatment of influenza-like syndrome. Br J Clin Pharmacol 1989; 3: 329-335.

4 Kleijnen J, Knipschild P, Ter Riet G. Clinical trails of homeopathy. BMJ 1991; 302: 316-323.

5 Boissel JP, Cucherat M, Haugh M, et al. Clinical literature review on the effective of homeopathy: overview of data from homeopathic medicine trials. Homeopathic Medicine Research Group. Report to the European Commission, Brussels, 1996; Chapter 11, 195-210.

6 Linde K, Clausius N, Ramirez G, et al. Are the clinical effects of homeopathy placebo effects? A meta-analysis of placebo-controlled trials. Lancet 1997; 350: 834-843.

7 Schroyens F. Synthesis. In: Schroyens F (ed.), Repertorium homeopathicum syntheticum. London: Homeopathic Book Publishers, 1998.

8 Gemmell DM. Everyday homeopathy. A safe guide for self-treatment. Beaconsfield: Beaconsfield Publishers, 1987.

9 Hunton M. Endometriosis and homeopathy: an audit study of 8 consecutive patients. Br Homeopath J 1993; 82: 92-96.

10 Queralt Gimeno ML. Homeopathic treatment of ovarian cysts: a series of 40 cases. Br Homeopath J 1991; 80: 143-148.

11 Jacobs J. Is homeopathy effective for hot flashes and other estrogenwithdrawal symptoms in breast cancer survivors? J Am Inst Homeopath 1999; 92: 72-77.

12 Clover A. Improving the success of homeopathy 2 (conference proceedings). London: Royal London Homeopathic Hospital, $1999 ; 76$.

13 Clover A. Patient benefit survey: Tunbridge Wells Homeopathic Hospital 1997. Br Homeopath J 2000; 89(Suppl. 1): S45.

14 Balzarini A, Felisi E, Martini A, et al. Efficacy of homeopathic treatment of skin reactions during radiotherapy for breast cancer: a randomised double-blind clinical trail. Br Homeopath J 2000; 89: $8-12$.

15 Clover A, Last P, Fisher P, et al. Complementary cancer therapies and quality of life. Complement Ther Med 1995; 3: 129-133.

16 Thompson E. The homeopathic approach to symptom control in the cancer patient - an observational study. Oral presentation at the European Association Palliative Care Congress, Geneva, Switzerland, September 1999.

17 Katz T. Adult survivors of sexual abuse. Br Homeopath J 1996; 85: 214-220.

18 English JM. Sexual complaints and their homeopathic medicines. $\mathrm{Br}$ Homeopath J 1996; 85: 221-229. 